\title{
Pathogenesis of gastrinomas associated with multiple endocrine neoplasia type 1
}

\section{M Pritchard}

\section{Deletion of the second allele of the tumour suppressor gene MEN1 is assoiated with development of duodenal gastrin-secreting microtumours in MEN1}

Z

ollinger-Ellison syndrome results from hypergastrinaemia and gastric hyperacidity. The disorder is clinically characterised by recurrent peptic ulcer disease, gastroesophageal reflux disease and, often, diarrhoea. ${ }^{12}$ The syndrome is caused by gastrin-secreting tumours (gastrinomas), which can arise either sporadically (approximately 70$75 \%$ ) or in association with the autosomal dominant inherited condition, multiple endocrine neoplasia type l (MENl; approximately $25-30 \%){ }^{3}$ The MENI syndrome is also associated with a range of endocrine tumours that predominantly arise in the parathyroid glands, anterior pituitary gland and pancreas. ${ }^{45}$ Sporadic gastrinomas are usually single and are most commonly located in the pancreas, although some are found in the duodenum. By contrast, gastrinomas found in patients with MENI are usually multiple and are most often located in the duodenal wall. Although multiple endocrine macrotumours and microtumours are also commonly found in the pancreas of patients with MENl, these neoplasms usually secrete a variety of other hormones and are rarely gastrinomas. ${ }^{6}$ These observations on the location and multiplicity of tumours have implications for the surgical resection of gastrinomas, and it is now advised that even when pancreatic tumours are shown by imaging studies, duodenotomy should be performed in all cases that seem to be associated with MEN1. ${ }^{78}$

MENI is caused by germline mutations in the tumour suppressor MENI gene located on chromosome 11q13.9 ${ }^{10}$ This gene encodes the protein menin, whose functions have not yet been fully defined, particularly as it has been shown to bind several (mostly nuclear) partner proteins and disrupt several signalling pathways. ${ }^{11}$ A number of mouse models in which the MENI gene is disrupted have been generated, and many of these transgenic animals have developed tumours in the tissues (such as pancreas and parathyroid) that are also affected in the human syndrome. However, gastrinomas are only rarely observed in MenI ${ }^{+/-}$mice. ${ }^{101213}$

Recently, there has been considerable interest in the pathogenesis of endocrine tumours in patients with MEN1. It has recently been proposed that tumours may arise from precursor lesions. For example, microadenomas have been identified in the pancreas of patients with MENl, but currently there is a debate as to whether these arise from islets ${ }^{14}$ or from ductal epithelium..$^{15}$ Pancreatic islet hyperplasia has also been identified in some types of $M e n I^{+/-}$mice. ${ }^{13}$ Recently Anlauf et $a l^{16}$ at the University of Kiel, Kiel, Germany, have investigated the pathogenesis of duodenal gastrinomas arising in patients with MENl. In a paper published in Gastroenterology ${ }^{16}$ this group reported distinctive proliferative hyperplastic gastrin cell lesions in the non-tumorous duodenum of patients with MENI-associated multifocal duodenal gastrinomas. The authors proposed that these lesions were preneoplastic, in an analogous fashion to C cell hyperplasia in medullary carcinoma of the thyroid in the setting of $\mathrm{MEN}^{17}$ and enterochromaffin-like cell hyperplasia in type 1 gastric carcinoids associated with autoimmune chronic atrophic gastritis and hypergastrinaemia. ${ }^{18}$

In this issue of Gut, Anlauf et al ${ }^{19}$ (see page 637) have taken their investigations further and have analysed the genetic changes that occur in duodenal gastrinomas and their previously identified precursor lesions. Patients with MEN1 display heterozygous germline mutations in the MENI gene. According to Knudson's $\mathrm{s}^{20}$ two-hit hypothesis of tumour development, the formation of MEN1-associated tumours will involve additional somatic inactivation of the wild-type MENI allele on chromosome 11q13. This may result in loss of a part or all of the chromosome 11. PCR-based techniques have previously been used to demonstrate loss of heterozygosity $(\mathrm{LOH})$ at 1lq13 in approximately half the cases of a variety of MEN1-associated macrotumours including gastrinomas. ${ }^{21}$ Other cases may harbour intragenic mutations that inactivate the gene but do not lead to allelic loss, and that would not be detected by this technique. ${ }^{22}$ PCR-based methods involving microdissection are not currently precise enough to allow analysis of genetic changes occurring in individual cells. The authors have therefore used a novel combined fluorescence in situ hybridisation and immunofluorescence technique to simultaneously detect allelic deletions and hormone expression in individual duodenal neuroendocrine cells.

The authors initially analysed 28 duodenal gastrin-producing neuroendocrine tumours from six patients with ZollingerEllison syndrome and MEN1, and found $\mathrm{LOH}$ for $11 \mathrm{ql} 3$ in $46 \%$ of patients. ${ }^{19}$ Different tumours from the same patient often showed different patterns of allelic loss (allelic loss of 11q13 only, loss of the whole chromosome or no LOH), suggesting that each gastrinoma arising in an individual patient developed as a result of an independent second hit. In addition to the tumours studied, all six patients showed several foci of hyperplastic gastrin cells. ${ }^{16}$ However, none of these lesions showed $\mathrm{LOH}$ at the tested loci. The authors therefore conclude that the hyperplastic lesions (which are proposed to be preneoplastic) retain both MENI alleles and that allelic loss (or alternatively MENI gene mutation, which may be present in 54\% of tumours not demonstrating $\mathrm{LOH}$ ) is responsible for the initial development of neoplastic lesions. Similar findings were made in five somatostatin-secreting tumours from the same patients, two of which showed LOH at the 1lq13 locus, whereas there was no LOH in hyperplastic somatostatin cell lesions. ${ }^{19}$

Several questions still need to be answered. Perhaps one of the more intriguing questions is the cause of hyperplasia of gastrin-secreting and somatostatinsecreting cells in the duodenums of patients with MEN1, especially as these lesions do not show LOH of the MENI gene. Could the hyperplasia of these cells be hormonally regulated as is observed in the enterochromaffin-like cell hyperplasia associated with hypergastrinaemia, or is it simply the result of a germline mutation in a single MENI gene? If a germline mutation in a single $M E N 1$ gene is the case, why are the lesions predominantly composed of gastrin-secreting or somatostatin-secreting cells rather than other endocrine cell types? Also, as analysis of the hyperplastic lesions showed no LOH at 11q13, it remains to be answered whether these lesions are truly preneoplastic. Is it possible that these lesions harbour inactivating intragenic mutations that do not lead to LOH? This 


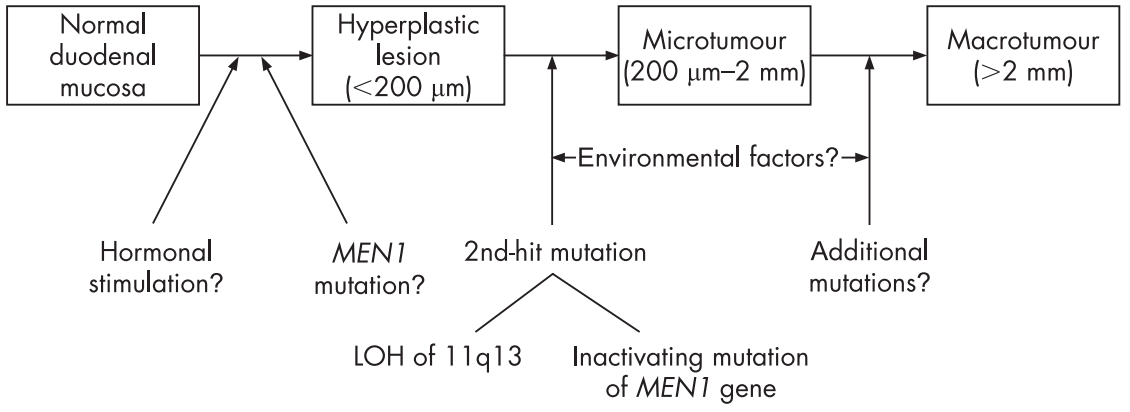

remains to be tested. Do gastrinomas arising in MENl arise within foci of gastrin-cell hyperplasia or can they arise from any cell that acquires a second-hit mutation? Moreover, do any external or luminal factors cause the second hit to develop? Even if the hyperplastic lesions are not truly preneoplastic, they may be clinically useful as their detection by biopsy in a patient with Zollinger-Ellison syndrome suggests that the condition is likely to be MEN1-associated rather than being the sporadic form.

In conclusion, the study by Anlauf et $a l^{19}$ has enhanced our knowledge of the pathogenesis of MEN1-associated gastrinomas. Multiple tumours seem to arise in susceptible patients as a result of multiple independent second-hit mutations in the MEN1 gene (fig 1). The described combined fluorescence in situ hybridisation/ immunofluorescence technique is a very powerful approach for analysing genetic changes in hyperplastic lesions and microtumours involving a few cells and avoids the potential errors that may result from microdissection. Further investigations of the significance of the duodenal gastrin and somatostatin hyperplastic lesions found in patients with MENI are warranted. From a clinical perspective, it is now crucial at the time of diagnosis to determine, if possible, whether a patient with Zollinger-Ellison syndrome has a sporadic or MEN1-associated gastrinoma, because the different locations and numbers of tumours in these two contexts now suggest different therapeutic approaches, particularly with regard to surgery.

Gut 2007;56:606-607.

doi: 10.1136/gut.2006.113985

Correspondence to: $\operatorname{Dr}$ D M Pritchard, Division of Gastroenterology, School of Clinical Sciences, University of Liverpool, The Henry Wellcome Laboratory, Nuffield Building, Crown Street, Liverpool L69 3GE, UK; mark. pritchard@liv.ac.uk

Competing interests: None.

\section{REFERENCES}

1 Jensen RT. Gastrinomas: advances in diagnosis and management. Neuroendocrinology 2004;80/Suppl 1):23-7.

2 Campana D, Piscitelli L, Mazzotta E, et al. Zollinger-Ellison syndrome. Diagnosis and therapy. Minerva Med 2005;96:187-206.

3 Gibril F, Jensen RT. Zollinger-Ellison syndrome revisited: diagnosis, biologic markers, associated inherited disorders, and acid hypersecretion. Curr Gastroenterol Rep 2004;6:454-63.

4 Brandi ML, Gagel RF, Angeli A, et al. Guidelines for diagnosis and therapy of MEN type 1 and type 2 $J$ Clin Endocrinol Metab 2001;86:5658-71.

5 Doherty GM. Multiple endocrine neoplasia type 1. J Surg Oncol 2005:89:143-50.

6 Anlauf M, Garbrecht N, Henopp T, et al. Sporadic versus hereditary gastrinomas of the duodenum and pancreas: distinct clinico-pathological and epidemiological features. World J Gastroentero 2006; 12:5440-6.

7 Norton JA. Surgical treatment and prognosis of gastrinoma. Best Pract Res Clin Gastroenterol 2005; 19:799-805

8 Norton JA, Alexander HR, Fraker DL, et al. Does the use of routine duodenotomy (DUODX) affect rate of cure, development of liver metastases, or survival in patients with Zollinger-Ellison syndrome? Ann Surg 2004;239:617-25.

9 Chandrasekharappa SC, Guru SC, Manickam P, et al. Positional cloning of the gene for multiple
Figure 1 Proposed mechanism for pathogenesis of duodenal gastrinomas in multiple endocrine neoplasia type 1 (MEN1). $\mathrm{LOH}$. Loss of heterozygosity. endocrine neoplasia-type 1. Science 1997;276:404-7.

10 Marx SJ. Molecular genetics of multiple endocrine neoplasia types 1 and 2. Nat Rev Cancer 2005:5:367-75.

11 Agarwal SK, Kennedy PA, Scacheri PC, et al. Menin molecular interactions: insights into normal functions and tumorigenesis. Horm Metab Res 2005;37:369-74

12 Crabtree JS, Scacheri PC, Ward JM, et al. A mouse model of multiple endocrine neoplasia, type 1 develops multiple endocrine tumors. Proc Natl Acad Sci USA 2001;98:1118-23.

13 Loffler KA, Biondi CA, Gartside M, et al. Broad tumor spectrum in a mouse model of multiple endocrine neoplasia type 1. Int J Cancer 2007; 120:259-67.

14 Anlauf M, Schlenger R, Perren A, et al. Microadenomatosis of the endocrine pancreas in patients with and without the multiple endocrine neoplasia type 1 syndrome. Am J Surg Pathol 2006;30:560-74

15 Vortmeyer AO, Huang S, Lubensky I, et al. Nonislet origin of pancreatic islet cell tumors. J Clin Endocrinol Metab 2004:89:1934-8.

16 Anlauf $M$, Perren $A$, Meyer $C L$, et al. Precursor lesions in patients with multiple endocrine neoplasia type 1-associated duodenal gastrinomas. Gastroenterology 2005;128:1187-98.

17 Guyetant S, Blechet C, Saint-Andre JP. C-cell hyperplasia. Ann Endocrinol(Paris), 2006;67:190-7.

18 Burkitt MD, Pritchard DM. Review article: pathogenesis and management of gastric carcinoid tumours. Aliment Pharmacol Ther 2006:24:1305-20.

19 Anlauf M, Peren A, Henopp T, et al. Allelic deletion of the MEN1 gene in duodenal gastrin and somatostatin cell neoplasms and their precursor lesions. Gut 2007;56:637-44.

20 Knudson AG. Two genetic hits (more or less) to cancer. Nat Rev Cancer 2001;1:157-62.

21 Debelenko LV, Zhuang Z, Emmert-Buck MR, et al. Allelic deletions on chromosome 11q13 in multiple endocrine neoplasia type 1-associated and sporadic gastrinomas and pancreatic endocrine tumors. Cancer Res 1997; 57:2238-43.

22 Pannett AA, Thakker RV. Somatic mutations in MEN type 1 tumors, consistent with the Knudson "two-hit" hypothesis. J Clin Endocrinol Metab $2001 ; 86: 4371-4$ 


\section{Avoiding unnecessary surgery in irritable bowel syndrome}

\section{George F Longstreth}

\section{Protecting patients with IBS from the risks and costs of unnecessary surgery}

S urgery has no role in treating irritable bowel syndrome (IBS), the prototypic functional bowel disorder. ${ }^{1}$ Nevertheless, since Ryle ${ }^{2}$ reported a high appendectomy rate in such patients nearly 80 years ago, descriptive case series, population-based studies and comparisons of patients with IBS with subjects without IBS and patients with inflammatory bowel disease ${ }^{3-8}$ have shown that patients with IBS are predisposed to surgery. In two large groups of patients with IBS, cholecystectomy and hysterectomy, which are mainly elective procedures, were increased threefold and twofold, respectively, and the primarily emergency operation, appendectomy, was also increased twofold. ${ }^{57}$ Other abdominopelvic operations, especially colon resection, are also increased, ${ }^{7}$ as is back surgery. ${ }^{5}$ Much of this increased surgery must be unnecessary, and high surgical rates have been reported from the UK, Western Europe, Scandinavia, North America, Latin America and South Africa. The association of IBS with normal appendiceal pathology after urgent appendectomy, as reported by investigators from Taiwan in this issue, (see page 655) further emphasises the worldwide importance of avoiding unnecessary surgery in IBS.

How much surgery is unnecessary on patients with IBS and the reasons for this problem are difficult to ascertain from studies that are retrospective and lack information on surgical pathology. Furthermore, unlike appendicitis, gallstones and uterine pathology are often asymptomatic and are not life threatening, so their documentation does not necessarily mean that surgery was needed. If hysterectomy is performed for dysfunctional uterine bleeding and chronic pelvic pain (CPP), consistent elimination of bleeding with variable pain relief complicates assessment of the overall benefit. Nevertheless, the available data identify preoperative misdiagnosis of the aetiology of pain as a major reason for increased abdominopelvic surgery in patients with IBS. The prospective study by Lu et al $^{9}$ provides the best evidence to date of mistaken diagnosis of appendicitis. Anxiety, atypical pain and physical examination findings, a lower neutrophil count, less use of computed tomography (CT), and IBS symptoms independently predicted a normal appendix. In patients with cholecystectomy, preoperative gas symptoms, ${ }^{10}{ }^{11}$ constipation, ${ }^{11}$ psychotropic drug use, ${ }^{11}$ psychological symptoms and broadly defined dyspepsia ${ }^{12}$ predicted persistent symptoms, suggesting that the patients had functional pain before surgery. In women undergoing elective hysterectomy, CPP without identified pathology was more often the only preoperative diagnosis in those with IBS than in those without IBS; in those who preoperatively stated that their surgery was for pain there was a higher proportion of patients with IBS than in those not having hysterectomy for pain. These findings, similar surgical pathology in the two groups and a trend toward lower pain improvement after 1 year in the women with IBS, suggest that IBS caused the pain that hysterectomy was intended to relieve in some patients. ${ }^{13}$

Increased surgery contributes to a cycle of events that often characterise the ineffective care of severe IBS and functional abdominal pain syndrome (FAPS),${ }^{14}$ which shares psychosocial correlates and pain behaviours with IBS but lacks bowel dysfunction (fig 1). ${ }^{15}$ Research findings on patients and doctors, and widespread clinical experience, support this sequence of events. Initially, patients' pain and disability lead to frequent visits to doctors who may feel "drained" because of their inability to diagnose the disorder, improve or cure it, and to feel gratified from caring for them. ${ }^{16}{ }^{17}$ They may lack important knowledge about $\mathrm{IBS}^{17}$ minimise the seriousness of the patients' symptoms, ${ }^{18}$ and believe that IBS is more difficult to diagnose in women than men but that men with IBS are more difficult to manage. ${ }^{19}$ When the patients urgently seek care at emergency departments, the doctors may not have complete medical records or contact with the patients' doctors, and they may focus on acute illness and fail to recognise the pain as an exacerbation of a chronic disorder. Emergency physicians may concentrate on excluding "organic" disease and consult surgeons who have little experience with functional pain syndromes, and fail to consider IBS and FAPS. Doctors request more radiology and laboratory tests for patients with $\mathrm{IBS}_{,}{ }^{20}$ including gallbladder procedures and endoscopic retrograde cholangiopancreatography, ${ }^{7}$ than for patients without IBS. Patients with IBS receive prescriptions for many categories of drugs and have increased rates of hospitalisation compared to contols without IBS. ${ }^{20}$ They are often referred to gynaecologists for CPP, and IBS was the most common diagnosis in one CPP clinic, accounting for $37 \%$ of cases. $^{21}$ Therefore, non-gastroenterologists and biased or inadequately knowledgeable practitioners contribute to the care of many of the most severely affected patients with IBS.

This cycle of intense, misdirected medical activity ("furor medicus"), including unnecessary surgery, does not help patients with IBS; rather, it promotes or fails to alleviate maladaptive ("catastrophising") coping, alexithymia, psychiatric distress (anxiety and depression), and somatic and visceral hypervigilence (symptom-attentive behaviour). These psychosocial disturbances contribute to the brain-gut dysregulation that underlies the pathophysiology of IBS and other functional gastrointestinal disorders. ${ }^{22}$

Psychosocial factors have long been associated with polysurgery and persistent postoperative abdominal pain. Canadian surgeons reported, 40 years ago, that patients with "personality defects", including depression and drug addiction, tended to become "albatrosses" after gastrectomy, complaining of continued abdominal pain and other symptoms. This experience prompted the surgeons to advise ulcer surgery on such patients only if they had ulcer complications. ${ }^{23}$ DeVaul and Faillace ${ }^{24}$ described patients with a mean of about 10 major surgeries, especially abdominopelvic operations for painful conditions. Most were women, and many had a history of childhood abuse or deprivation and continued to insist on cure of their pain. Creed found that patients who had severe stressful life events during the year before emergency appendectomy, or had psychiatric symptoms, were more likely to have a non-inflamed appendix and persistent pain 1 year postoperatively than other patients. ${ }^{25}$ It is likely that many of the patients in these surgical series had severe IBS or FAPS. 


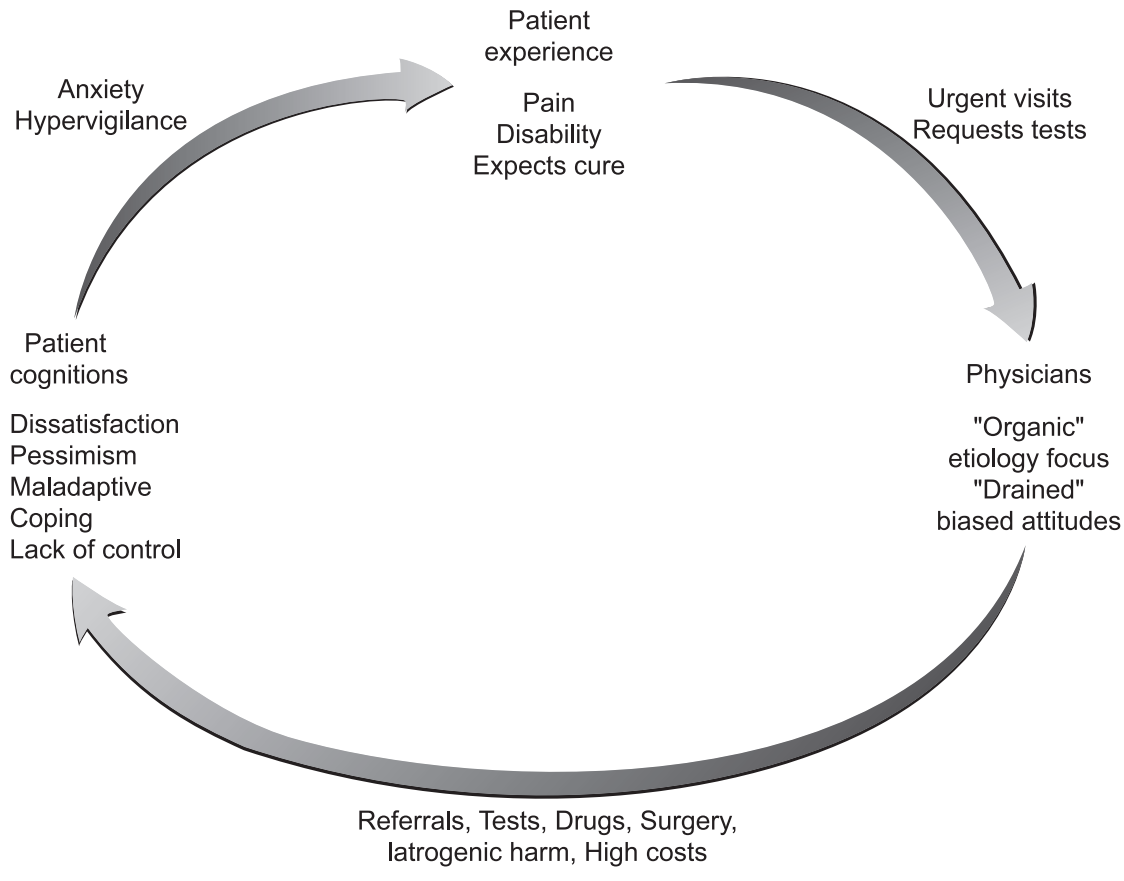

Figure 1 Typical cycle of ineffective management of patients with severe irritable bowel syndrome or functional abdominal pain syndrome. ${ }^{15}$ Reprinted with permission.

What can doctors do to reduce unnecessary surgery in these patients? More research on the effectiveness of specific measures would be valuable, but the study by $\mathrm{Lu}$ et al, ${ }^{9}$ previous research observations, and basic clinical principles support both general and operationspecific approaches.

\section{GENERAL PRINCIPLES}

Emotional descriptions of pain-for example, "It is killing me" - that are out of proportion to examination findings or laboratory test or imaging results should raise the question of functional pain. Narcotic-seeking behaviour can be another clue. The medical and surgical history can be especially valuable. When a patient presents to an emergency department with acute abdominal pain, the doctor should seek information on previous episodes of similar pain through both the interview and record review, which can reveal previous visits for severe pain that the patient does not report. The presence of other painful disorders that have not been satisfactorily relieved and a history of abdominopelvic surgery for pain, especially if it was unsuccessful, are also important. The interview should attempt to disclose recent emotional stress, chronic anxiety, depression and a detrimental change in the family or cultural milieu or social support.

Abdominal examination can reveal four characteristics of patients with functional pain: lack of autonomic arousal, multiple surgical scars with uncertain indications, the "closed eyes sign" (eye closure during palpation) and the "stethoscope sign" (the detection of less tenderness during pressure with a stethoscope than with palpation). ${ }^{14}$ Carnett's test accurately distinguishes visceral pain from abdominal wall pain when abdominal tenderness increases during abdominal muscle contraction. In a series of outpatients with chronic abdominal wall pain, 22\% also had IBS ${ }^{26}$; such patients can have somatic and visceral pain together or at different times, and both types of pain can lead to unneeded surgery. Chronic abdominal wall pain is suggested as a cause of gynaecologists' patients' CPP by published descriptions of focal abdominal tenderness. ${ }^{27}$

In patients presenting with acute pain, a request for abdominal imaging (eg, CT) should depend on other findings. Furthermore, patients with IBS who have undergone such procedures with normal results are unlikely to benefit from repeat testing unless their symptoms change. CT scan is rarely diagnostic in outpatients with non-acute abdominal pain who lack warning symptoms or signs, but is commonly reported to show abnormalities unrelated to the pain that result in specialty referral, additional imaging procedures and surgery that are usually fruitless or do not benefit the patient. ${ }^{28}$

The counterproductive management cycle, including unnecessary surgery, is best prevented or stopped though the care of a single supervising doctor who promotes a therapeutic doctor-patient interaction through effective communication, attention to psychosocial factors, legitimising symptoms, wise use of diagnostic tests and consultations, confident diagnosis, and individualised therapy that may include psychotherapy and central nervous system pharmacotherapy. ${ }^{15}$ The most worried and disabled patients do not accept the diagnosis and learn to cope with their symptoms until the testing and referrals stop. It is especially important to prevent urgent emergency department visits and unnecessary specialist referrals. Primary physicians can take the main responsibility for the care of many patients but, depending on the circumstances, sometimes a gastroenterologist must assume this role.

\section{APPENDECTOMY}

The study of Lu et al emphasises that some unnecessary appendectomies might be prevented by a proper general approach, including documenting an atypical history and examination findings, anxiety, a normal neutrophil count and obtaining CT when needed to confirm appendicitis. However, 100\% preoperative diagnostic accuracy is not achievable, and clinical judgment must prevail.

\section{CHOLECYSTECTOMY}

Although most patients with IBS localise their worst pain to the lower abdomen, they can have pain anywhere in the abdomen and often have dyspepsia. Increasingly, experienced doctors recognise typical biliary pain as severe epigastric and/or right upper quadrant in location, often accompanied by vomiting, and $\geqslant 1 \mathrm{~h}$ in duration at intervals of weeks to months. Variability in these characteristics occurs, but chronic, daily dyspepsia, for example, when the patient says it occurs "all the time," is unlikely to be relieved by cholecystectomy. Generally, patients whose symptoms and basic laboratory test results are not typical of biliary disease are not helped by ultrasonographic examination, and failure to document their asypmptomatic gallstones may prevent cholecystectomy by a surgeon who misinterprets the aetiology of their pain.

\section{HYSTERECTOMY}

Gynaecological referral should be considered for women with abdominal or "pelvic" pain and menstrual abnormalities, other gynaecological symptoms or when the relation of pain with bowel function is uncertain. There is marked similarity between the psychosocial and behavioural aspects of CPP and IBS (eg, depression and a history of sexual or physical abuse), ${ }^{21}$ so the general principles of managing IBS also apply to the 
care of patients with CPP. Furthermore, the high proportion of women who have IBS among gynaecologists' patients with CPP suggests that in some cases their "pelvic" pain would be regarded as abdominal pain by gastroenterologists. Unnecessary pelvic surgery is best avoided through collaboration between the patient's gastroenterologist and gynaecologist.

Additional prospective studies on patients with IBS undergoing surgery could help identify more associations between patient features and unnecessary surgery. However, current knowledge can protect many patients from the risks and costs of unneeded surgery.

Gut 2007;56:608-610.

doi: $10.1136 /$ gut.2006.115006

Correspondence to: D. G F Longstreth, Kaiser Permanente Medical Center, 4647 Zion Avenue, San Diego, CA 92120, USA; george.f.

longstreth@kp.org

Competing interests: None.

\section{REFERENCES}

1 Drossman DA, Corazziari E, Delvaux MM, et al eds. Rome III:the functional gastrointestinal disorders.3rd edn. McLean, VA: Degnon Associates, 2006.

2 Ryle JA. Chronic spasmodic affections of the colon and the diseases which they simulate. Lancet 1928:2:1115-19.

3 Chaudary NA, Truelove SC. The irritable colon syndrome: a study of the clinical features, predisposing causes, and prognosis in 130 cases. Q J Med 1962;31:307-23.
4 Schmulson MJ, Valdovinos Días MA. Utilización de recursos médicos por los pacientes con syndrome de intestino irritable en un hospital de tercer nivel. Rev Gastroenterol Mex 1998:63:6-10.

5 Longstreth GF, Yao JF. Irritable bowel syndrome and surgery: a multivariable analysis. Gastroenterology 2004; 126:1665-73.

6 Hasler WL, Schoenfeld P. Systematic review: abdominal and pelvic surgery in patients with irritable bowel syndrome. Aliment Pharmacol Ther 2003; 17:997-1005.

7 Cole JA, Yeaw JM, Cutone JA, et al. The incidence of abdominal and pelvic surgery among patients with irritable bowel syndrome. Dig Dis Sci 2005;50:2268-75

8 Martín González RA, Ruiz MR. Síndrome de intestino irritable y cirugías: análisis retrospectivo. Rev Gastroenterol Mex 2006;71(Suppl 2):130.

9 Lu C-L, Liu C-C, Fuh J-L, et al. Irritable bowel syndrome and negative appendectomy: a prospective multivariable investigation. Gut 2007;56:655-60.

10 Weinert CR, Arnett D, Jacobs D, et al. Relationship between persistence of abdominal symptoms and successful outcome after cholecystectomy. Arch Intern Med 2000; 160:989-95.

11 Luman W, Adams WH, Nixon SN, et al. Incidence of persistent symptoms after laparoscopic cholecystectomy; a prospective study. Gut 1996;39:863-6

12 Lorusso D, Porcelli P, Pezzolla F, et al. Persistent dyspepsia after laparoscopic cholecystectomy. The influence of psychological factors. Scand J Gastroenterol 2003:38:653-8.

13 Longstreth GF, Preskill DB, Youkeles L. Irritable bowel syndrome in women having diagnostic laparoscopy or hysterectomy. Relation to gynecologic features and outcome. Dig Dis Sci 1990;35:1285-90.

14 Drossman DA. Functional abdominal pain syndrome. Clin Gastroenterol Hepatol 2004;2:353-65.

15 Longstreth GF, Drossman DA. Severe irritable bowel syndrome and functional abdominal pain syndromes: managing the patient and health care costs. Clin Gastroenterol Hepatol 2005:3:397-400.
16 Drossman DA. Challenges in the physician-patient relationship: feeling drained. Gastroenterology 2001;121:1037-8

17 Longstreth GF, Burchette RJ. Family practitioners attitudes and knowledge about irritable bowel syndrome. Effect of a trial of physician education. Fam Pract 2003;20:670-4

18 Dalton CB, Drossman DA, Hathaway JM, et al. Perceptions of physicians and patients with organic and functional gastrointestinal diagnoses. Clin Gastroenterol Hepatol 2004;2:121-6.

19 Borum ML. Physician perception of IBS managemen in women and men. Dig Dis Sci 2002;47:236-7.

20 Longstreth GF, Wilson A, Knight K, et al. Irritable bowel syndrome, health care use, and costs: a U.S managed care perspective. Am J Gastroenterol 2003;98:600-7.

21 Lamvu G, Williams R, Zolnoun D, et al. Long-term outcomes after surgical and nonsurgical management of chronic pelvic pain: one year after evaluation in a pelvic pain clinic. Am J Obstet Gynecol 2006; 195:591-600.

22 Jones MP, Dilley JB, Drossman DA, et al. Brain-gut connections in functional $\mathrm{Gl}$ disorders: anatomic and physiologic relationships. Neurogastroenterol Motil 2006; 18:91-103.

23 Johnstone FRC, Holubitsky IB, Debas HT. Postgastrectomy problems in patients with personality defects: the "albatross" syndrome. Can Med Assoc J 1967;96:1559-64.

24 DeVaul RA, Faillace LA. Persistent pain and illness insistence. A medical profile of proneness to surgery. Am J Surg 1978;135:828-33.

25 Creed F. Life events and appendicectomy. Lancet 1981;1:1381-5.

26 Costanza CD, Longstreth GF, Liv AL. Chronic abdominal wall pain: clinical features, health care costs, and long-term outcome. Clin Gastroenterol Hepatol 2004;2:395-9.

27 Leserman J, Zolnoun D, Meltzer-Brody S, et al Identification of diagnostic subtypes of chronic pelvic pain and how subtypes differ in health status and trauma history. Am J Obstet Gynecol 2006; 195:554-61.

28 Master SS, Longstreth GF, Liu AL. Results of computerized tomography in family practitioners patients with non-acute abdominal pain. Fam Pract 2005;22:474-7.

\section{The role of Escherichia coli in inflammatory bowel disease}

\section{Jonathan M Rhodes}

\section{Mucosa-associated E Coli are reported to be increased in Crohn's disease}

$\mathrm{T}$ here is a widespread assumption that both of the major inflammatory bowel diseases, Crohn's disease and ulcerative colitis, arise as a result of a host response to intestinal bacteria. Evidence to support this includes the involvement of non-pathogenic bacteria in the development of colitis in genetically altered animals, knowledge that the Crohn's disease-associated gene NOD2/CARD15 is a receptor for bacterial cell-wall peptidoglycan, the common presence of circulating anti-bacterial antibodies in Crohn's disease, and the role of known pathogens in precipitating relapse in ulcerative colitis. ${ }^{1}$ We still need to know which bacteria are the culprits, where they are (intraluminal, intramucosal, intracellular) and whether there is an abnormal host response to "commensal" bacteria or whether the bacteria themselves have pathogenic features.

Study of the gut microbiota is not easy. The human gut contains $500-1000$ bacterial species ${ }^{2}$ and around $80 \%$ of these have yet to be cultured. ${ }^{3}$ There is growing evidence that the bacteria that are closely related to or adherent to the mucosa may be more relevant to mucosal inflammation than those in the faeces. Studies of the mucosa-associated bacteria are, however, affected by the method used. The colonic mucosa, unlike the small intestine, has a near-continuous mucus coat ${ }^{4}$ and bacteria adherent to the surface of this coat will differ in number and nature from those underneath the mucus. Moreover, the surface of the mucus layer, like the faeces, is likely to suit the growth predominantly of anaerobic bacteria, whereas mucus represents a significant barrier to oxygen diffusion, ${ }^{5}$ so the submucus niche may be relatively well oxygenated by the underlying mucosa and more suitable for micro-aerophilic bacteria. We have found that aerobic culture of colonoscopic biopsies after removal of the mucus layer with dithiothreitol is often sterile in control colons, whereas the colon in Crohn's disease and colon cancer contains increased bacterial numbers in this sub-mucus niche, more than half of which are $E$ coli, ${ }^{6}$ even though 


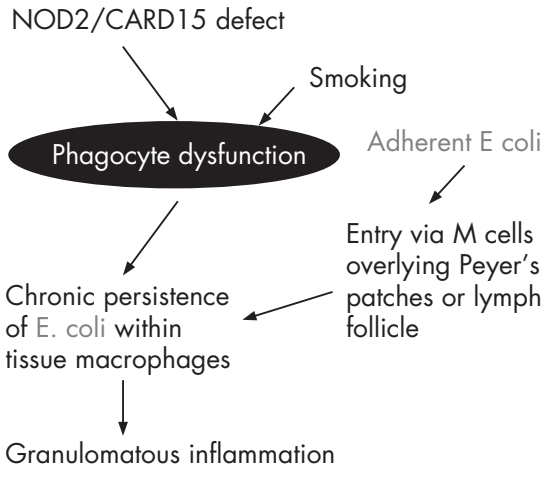

Figure 1 Models for involvement of $E$ coli in IBD pathogenesis: 1. Crohn's disease.

these organisms account for less than $1 \%$ of the faecal microbiota.

At least five independent groups have reported that mucosa-associated $E$ coli are increased in Crohn's disease ${ }^{6-10}$ and the study by Kotlowski et al in this issue ${ }^{11}$ (see page 669) makes this six. Two of the studies ${ }^{71}$ have also shown an increase in mucosa-associated $E$ coli in ulcerative colitis. One group has reported selective growth of the $E$ coli from distal ileal mucosal samples in Crohn's disease, ${ }^{8}$ whilst the others have reported on colonic mucosal samples. The present study adds particular weight to the potential importance of $E$ coli because of the initial screen that was used, which should have been able to pick up any bacteria that were overexpressed in the inflammatory bowel disease tissue samples. The study used ribosomal intergenic spacer analysis to identify DNA segments that were more commonly present (in about $70 \%$ ) in Crohn's disease and ulcerative colitis mucosal biopsies than controls (about $30 \%$ ). Five of these segments were then sequenced and all were found to contain $E$ coli DNA. Subsequent study focused on $E$ coli and again confirmed increased culture of $E$ coli from Crohn's disease samples and, to a lesser extent, from ulcerative colitis samples, compared with controls. There was a poor correlation between site of inflammation and presence of $E$ coli, in agreement with other studies that have tended to show that the same organisms can be identified from various sites within the same colon. ${ }^{67}$ This is compatible with the organisms having a causative role in the inflammation rather than merely colonising inflamed mucosa.

Where do the $E$ coli end up? In Crohn's disease but not ulcerative colitis there is good evidence of bacterial invasion into tissues and this is supported by the tendency for abscess and fistula formation. Some of the bacteria undoubtedly invade after a breach in the mucosa has already

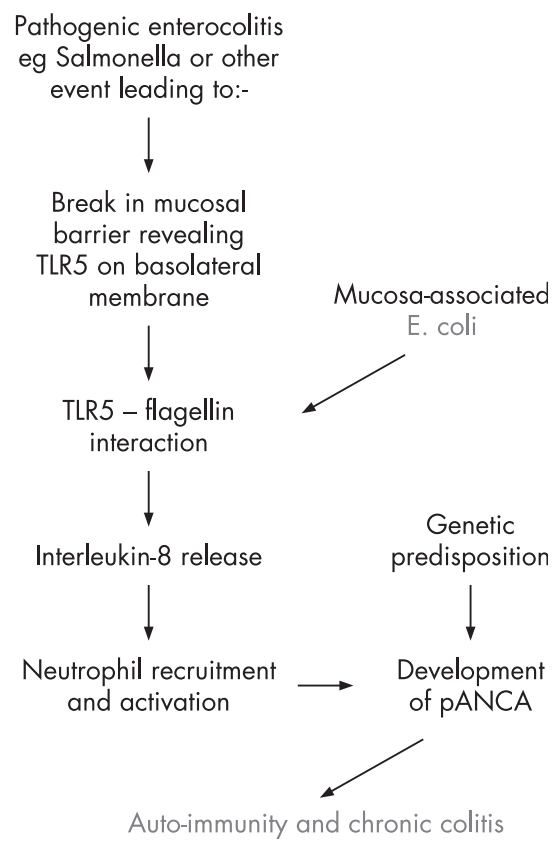

Figure 2 Models for involvement of $E$ coli in IBD pathogenesis: 2 . Ulcerative colitis.

occurred and these are likely to be a crossspectrum of the faecal microbiota. ${ }^{12}{ }^{13}$ Nevertheless, an immunohistochemical study using a broad range of anti-microbial antibodies showed a selective presence in Crohn's disease tissue of $E$ coli, Listeria and Streptococci, all within macrophages. ${ }^{14}$ Subsequent studies of Listeria have been contradictory $^{15}$ but $E$ coli DNA has also been identified within 12/15 Crohn's disease granulomas dissected out from tissue sections by laser-dissecting microscopy, compared with 1/10 control granulomas, although the same group also identified $M$ paratuberculosis within Crohn's disease granulomas using the same technique. ${ }^{16}$ The possibility that the $E$ coli may end up chronically replicating within tissue macrophages is supported by evidence that Crohn's disease $E$ coli isolates are particularly capable of replicating within macrophage vesicles in vitro when compared with laboratory control $E$ coli strains. ${ }^{17}$

What is the site of entry? Crohn's disease mucosal $E$ coli isolates have been shown to be better able than laboratory strains to adhere to and invade colon epithelial cell lines in culture. ${ }^{6}{ }^{8}$ However, this phenomenon is cell-line specific ${ }^{6}$ and there is little evidence that they are able to invade the normal colonic epithelial cells in vivo. Moreover, there is good evidence that bona fide invasive pathogens, such as Salmonella and Shigella, are unable to invade via normal colon epithelial cells and instead make their initial entry via the specialised $M$ cells within the dome epithelium overlying Peyer's patches in the distal ileum and lymphoid follicles in the colon. ${ }^{18} 19$ There is no mucus layer overlying the dome epithelium since it possesses no goblet cells. Moreover, the $\mathrm{M}$ cells lack the "fuzzy" glycocalyx that other small intestinal and colonic epithelial cells possess. ${ }^{20}$ If unequivocal pathogenic organisms need $M$ cells as a portal, it seems likely that the Crohn's E coli, which lack conventional pathogenicity genes, will also have to enter via the M cells. This fits well with evidence suggesting that the earliest lesions in Crohn's disease occur at Peyer's patches in the ileum and lymphoid follicles in the colon ${ }^{21}$ (fig 1).

What role could these $E$ coli have in ulcerative colitis? The study by Kotlowski and colleagues published here ${ }^{11}$ and also that by Swidsinski and colleagues ${ }^{7}$ both show increased mucosa-associated $E$ coli in ulcerative colitis, possibly to a slightly lesser extent than in Crohn's disease. The lack of association reported by others ${ }^{6}$ may reflect differences in sampling technique, such as removal of the mucus layer prior to culture. There is no good evidence for mucosal invasion by $E$ coli in ulcerative colitis and the typically continuous inflammation does not suggest any specific focus of inflammation around lymphoid follicles. It seems more plausible that, in ulcerative colitis, the mucosaassociated $E$ coli may interact with the surface epithelial cells without invasion. This would fit with the superficial nature of mild colitis and also with evidence of surface epithelial NFkappaB activation as a very early event. ${ }^{22}$ Another likely result of such interaction would be release from the epithelial cells of interleukin-8 (IL-8), a potent chemotactant for neutrophils. So far, most evidence suggests that bacteriainduced IL-8 release from colon epithelial cells is usually a consequence of flagellinToll receptor 5 (TLR5) interaction and it is notable that this can result from interaction even with $E$ coli strains that are conventionally regarded as "commensal". ${ }^{23}$ Since TLR5 is located on the basolateral aspect of the epithelial cells, this would require prior weakening of the mucosal barrier, as occurs experimentally with dextran sulphate, to allow flagellin to pass through the tight junctions and reach TLR5. ${ }^{24}$ This represents a plausible model for ulcerative colitis, ${ }^{25}$ perhaps with inflammation perpetuated by an auto-immune mechanism (fig 2).

Further work is needed to characterise the inflammatory bowel disease mucosaassociated $E$ coli and their mechanisms of interaction with epithelial cells. In many ways their adherence and invasion of epithelial cells in the absence of any of the typical pathogenicity genes, other than adhesins, is similar to the properties 
of uropathogenic $E$ coli; ${ }^{26} 27$ indeed they may be the same organisms. There is already a considerable literature on how uropathogenic $E$ coli interact with epithelial cells ${ }^{2628}$ and much of this may be relevant in the colon. This may include interaction with members of the carcinoembryonic antigen-cell adhesion molecule (CEACAM) family ${ }^{29-31}$ that are present in the glycocalyx, the "fuzzy coat" that underlies the mucus layer and overlies colon and small intestinal epithelial cells. The study by Kotlowski and colleagues takes this a step forward with the demonstration that the Crohn's disease $E$ coli isolates are more likely to be in phylogenetic groups B2 and D; groups that characteristically contain $E$ coli that are pathogenic at extra-intestinal sites and that tend to adhere to epithelial cells. $^{32}{ }^{33}$ The inflammatory bowel disease isolates are also shown commonly to possess serine protease autotransporters (SPATEs), some of which possess mucinase activity. ${ }^{34}$ This could explain why these organisms seem typically to have been found within ${ }^{35}$ or beneath ${ }^{6}$ the colonic mucus layer.

Evidence is thus accumulating that $E$ coli, probably "mildly pathogenic" by virtue of their possession of adhesion mechanisms and secretion of proteases, may have a causative role in inflammatory bowel disease. In Crohn's disease they probably invade the tissue, perhaps as a result of defective clearance by neutrophils, ${ }^{36}$ and chronically infect macrophages, whereas they may have a more superficial relationship with the mucosal surface in ulcerative colitis. Koch's postulates have yet to be fulfilled but it is intriguing that $E$ coli with a similar adherent and invasive phenotype have been shown to be associated with granulomatous colitis in boxer dogs. ${ }^{37} \mathrm{I}$ think we now have a new therapeutic target.

Gut 2007;56:610-612.

doi: $10.1136 /$ gut.2006.111872

Correspondence to: Professor Jonathan Rhodes, School of Clinical Sciences, University of Liverpool, Duncan Building, Daulby Street, Liverpool L69 3GA; rhodesjm@liverpool.ac.uk

Competing interests: JMR is a past/present member of advisory boards for Procter and Gamble, Schering-Plough, Chiesi, Falk, and Celltech/UCB, and, with the University of
Liverpool and Provexis UK, holds a patent for use of a soluble fibre preparation as maintenance therapy for Crohn's disease.

\section{REFERENCES}

1 Subramanian S, Campbell BJ, Rhodes JM. Bacteria in the pathogenesis of inflammatory bowel disease. Curr Opin Infect Dis 2006:19:475-84.

2 Egert M, de Graaf AA, Smidt H, et al. Beyond diversity: functional microbiomics of the human colon. Trends Microbiol 2006;14:86-91.

3 Eckburg PB, Bik EM, Bernstein CN, et al. Diversity of the human intestinal microbial flora. Science 2005;308: 1635-8.

4 Atuma C, Strugala V, Allen A, et al. The adherent gastrointestinal mucus gel layer: thickness and physical state in vivo. Am J Physiol Gastrointest Liver Physiol 2001;280:G922-9.

5 Saldena TA, Saravi FD, Hwang HJ, et al. Oxygen diffusive barriers of rat distal colon: role of subepithelial tissue, mucosa, and mucus gel layer. Dig Dis Sci 2000;45:2108-14.

6 Martin HM, Campbell BJ, Hart CA, et al. Enhanced Escherichia coli adherence and invasion in Crohn's disease and colon cancer. Gastroenterology 2004:127:80-93.

7 Swidsinski A, Ladhoff A, Pernthaler A, et al. Mucosal flora in inflammatory bowel disease. Gastroenterology 2002; 122:44-54.

8 Darfeuille-Michaud A, Boudeau J, Bulois $P$, et al. High prevalence of adherent-invasive Escherichia coli associated with ileal mucosa in Crohn's disease. Gastroenterology 2004; 127:412-21.

9 Mylonaki M, Rayment NB, Rampton DS, et al. Molecular characterization of rectal mucosaassociated bacterial flora in inflammatory bowe disease. Inflamm Bowel Dis 2005; 1 1:481-7.

10 Alpern J, Sasaki M, Sitaraman S, et al. Invasive E coli strains are increased in Crohn's disease. Gastroenterology 2006;130:A-362.

11 Kotlowski R, Bernstein CN, Sepehri S, et al. High prevalence of Escherichia coli belonging to the B2 and D phylogenetic groups in inflammatory bowe disease. Gut 2007:56:669-75.

12 Takesue $Y$, Ohge $H$, Uemura K, et al. Bacterial translocation in patients with Crohn's disease undergoing surgery. Dis Colon Rectum 2002;45: 1665-71.

13 Ambrose NS, Johnson M, Burdon DW, et al. Incidence of pathogenic bacteria from mesenteric lymph nodes and ileal serosa during Crohn's disease surgery. Br J Surg 1984;71:623-5.

14 Liu $Y$, van Kruiningen $H J$, West $A B$, et al. Immunocytochemical evidence of Listeria Escherichia coli, and Streptococcus antigens in Crohn's disease. Gastroenterology 1995; 108: 1396-404.

15 Chen W, Li D, Paulus B, et al. Detection of Listeria monocytogenes by polymerase chain reaction in intestinal mucosal biopsies from patients with inflammatory bowel disease and controls. J Gastroenterol Hepatol 2000; 15:1145-50.

16 Ryan P, Kelly RG, Lee G, et al. Bacterial DNA within granulomas of patients with Crohn's disease detection by laser capture microdissection and PCR. Am J Gastroenterol 2004;99:1539-43.

17 Bringer MA, Glasser AL, Tung $\mathrm{CH}$, et al. The Crohn's disease-associated adherent-invasive Escherichia coli strain LF82 replicates in mature phagolysosomes within $\mathrm{J774}$ macrophages. Cell Microbiol 2006;8:471-84.

18 Niedergang F, Kraehenbuhl JP. Much ado about M cells. Trends Cell Biol 2000;10:137-41.
19 Sansonetti PJ, Phalipon A. M cells as ports of entry for enteroinvasive pathogens: mechanisms of interaction, consequences for the disease process. Semin Immunol 1999;1 1:193-203.

20 Neutra MR, Mantis NJ, Frey A, et al. The composition and function of $M$ cell apical membranes: implications for microbial pathogenesis. Semin Immunol 1999;1 1:171-81

21 Fujimura $Y$, Kamoi R, lida $M$. Pathogenesis of aphthoid ulcers in Crohn's disease: correlative findings by magnifying colonoscopy, electron microscopy, and immunohistochemistry. Gut 1996;38:724-32

22 Bodger K, Halfvarson J, Dodson AR, et al. Altered colonic glycoprotein expression in unaffected monozygotic twins of inflammatory bowel disease patients. Gut 2006;55:973-77.

23 Bambou JC, Giraud A, Menard S, et al. In vitro and ex vivo activation of the TLR5 signaling pathway in intestinal epithelial cells by a commensal Escherichia coli strain. J Biol Chem 2004; 279:42984-92

24 Rhee SH, Im E, Riegler M, et al. Pathophysiological role of Toll-like receptor 5 engagement by bacterial flagellin in colonic inflammation. Proc Natl Acad Sci U S A 2005; 102:13610-5.

25 Gitter AH, Wullstein F, Fromm M, et al. Epithelial barrier defects in ulcerative colitis: characterization and quantification by electrophysiological imaging Gastroenterology 2001;121:1320-8.

26 Servin AL. Pathogenesis of Afa/Dr diffusely adhering Escherichia coli. Clin Microbiol Rev 2005; 18:264-92.

27 Marrs CF, Zhang L, Foxman B. Escherichia coli mediated urinary tract infections: Are there distinct uropathogenic $E$ coli (UPEC) pathotypes? FEMS Microbiol Letts 2005;252:183-90.

28 Mulvey MA. Adhesion and entry of uropathogenic Escherichia coli. Cell Microbiol 2002;4:257-71.

29 Berger CN, Billker O, Meyer TF, et al. Differential recognition of members of the carcinoembryonic antigen family by Afa/Dr adhesins of diffusely adhering Escherichia coli (Afa/Dr DAEC). Mol Microbiol 2004;52:963-83.

30 Frangsmyr L, Baranov V, Hammarstrom S. Four carcinoembryonic antigen subfamily members, CEA, NCA, BGP and CGM2, selectively expressed in the normal human colonic epithelium, are integral components of the fuzzy coat. Tumour Bio 1999;20:277-92.

31 Kuespert K, Pils S, Hauck CR. CEACAMs: their role in physiology and pathophysiology. Curr Opin Cell Biol 2006; 18:565-71.

32 Clermont O, Bonacorsi S, Bingen E. Rapid and simple determination of the Escherichia coli phylogenetic group. App Environ Microbiol 2000;66:4555-58.

33 Nowrouzian FL, Adlerberth I, Wold AE. Enhanced persistence in the colonic microbiota of Escherichia coli strains belonging to phylogenetic group B2: role of virulence factors and adherence to colonic cells. Microbes Infection 2006;8:834-40.

34 Parham NJ, Srinavasan U, Desvaux M, et al. PicU, a second serine protease autotransporter of uropathogenic Escherichia coli. FEMS Microbiol Letts 2004;230:73-83.

35 Schultsz C, Van Den Berg FM, Ten Kate FW, et al. The intestinal mucus layer from patients with inflammatory bowel disease harbors high numbers of bacteria compared with controls. Gastroenterology 1999;117:1089-97.

36 Marks DJ, Harbord MW, MacAllister R, et al. Defective acute inflammation in Crohn's disease: a clinical investigation. Lancet 2006;367:668-78.

37 Simpson KW, Dogan B, Rishniw M, et al. Adherent and invasive Escherichia coli is associated with granulomatous colitis in boxer dogs. Infect Immunity 2006;74:4778-92. 
Iron and $\mathrm{HCV}$

\section{Iron, haemochromatosis and thalassaemia as risk factors for fibrosis in hepatitis $C$ virus infection}

\section{Mark Thursz}

\section{Iron depletion is required in patients with $\mathrm{HCV}$ and iron overload to retard liver fibrosis}

$\mathrm{E}$ xcess iron is an important cause of liver damage. Aerobic metabolism generates oxygen species as a byproduct of the reduction of $\mathrm{O}_{2}$ but these are generally of low reactivity. The presence of transition metal ions such as iron $\left(\mathrm{Fe}^{2+}\right)$ catalyses the generation of highly reactive oxygen species, the most important of which is the hydroxyl radical $(\cdot \mathrm{OH})$.

$$
\begin{gathered}
\mathrm{Fe}^{2+}+\mathrm{H}_{2} \mathrm{O}_{2} \rightarrow \mathrm{Fe}^{3+}+{ }^{-} \mathrm{OH}+{ }^{\circ} \mathrm{OH} \\
\mathrm{H}_{2} \mathrm{O}_{2}+\mathrm{O} 2-^{-}-{ }^{(\mathrm{Fe})} \rightarrow{ }^{-} \mathrm{OH}+{ }^{\circ} \mathrm{OH}+\mathrm{O}_{2}
\end{gathered}
$$

The hydroxyl radical causes oxidation of lipids, lipoproteins, proteins, DNA and carbohydrates leading to injury to the cell membranes and genomic damage. Mitochondrial cell membranes are particularly susceptible to iron-catalysed, hydroxyl-mediated damage. ${ }^{1}$ Reactive oxygen species may also activate hepatic stellate cells and stimulate transformation into the collagen-producing myofibroblast phenotype associated with hepatic fibrosis ${ }^{2}$

The presence of excess iron in the liver in the absence of other aetiologies of liver damage may not be sufficient to cause liver disease. However, excess liver iron is now clearly recognised as a cofactor for the development of advanced fibrosis and cirrhosis in patients with hepatitis $\mathrm{C}$ virus (HCV) infection and alcohol-related liver disease. ${ }^{3-8}$

There is enormous variation in the rate at which fibrosis develops and the time taken for cirrhosis or decompensated liver disease to occur among patients with chronic HCV infection. ${ }^{9}{ }^{10}$ Certain factors influencing the progression of disease have been identified through cross-sectional and cohort studies so that some of this variation in the rate of fibrosis may be explained by sex of the patient, age at the time of infection and, in some studies, alcohol abuse. ${ }^{9-11}$ However, these factors only account for $20-30 \%$ of the variability in the progression rates of liver fibrosis leading many authors to conclude that much of the unexplained variability may be accounted for by patients' genetic background. Although a number of groups are currently searching for genes that influence liver fibrosis in patients with chronic viral hepatitis, only a small number has been identified so far Among these, a limited number has shown reproducibility and/or biological relevance. These include complement factor $\mathrm{V}$, coagulation factor $\mathrm{V}$, carnitine palmitoyltransferase $1 \mathrm{~A}$ and DEAD box polypeptide $5 .{ }^{12-14}$

It might be predicted that mutations in the HFE gene that cause iron overload and haemochromatosis would meet the requirements of biological plausibility and reproducibility as a cause for accelerated fibrosis. However, the association of HFE mutations and advanced fibrosis in patients with HCV infection is controversial. An initial report by Smith found that patients with HCV infection, who were heterozygous for the HFEC282Y mutation, had higher ferritin levels and were more likely to have stainable liver iron than patients who were homozygous for the wild-type HFE gene. ${ }^{15}$ Furthermore, in Smith's study, carriers of the HFE-C282Y mutation had more advanced fibrosis and 4 of 10 had cirrhosis. Although these findings have been replicated in other populations, ${ }^{16}{ }^{17}$ some studies, including the new one published in this issue of Gut, have not been able to show a clear association between HFE-C282Y and the degree of fibrosis. ${ }^{8}{ }^{18} 19$ Indeed, in our own population of over 900 European patients with chronic HCV infection, heterozygous carriage of HFE-C282Y was not associated with advanced or rapid liver fibrosis.

There are two possible explanations why the HFE-C282Y mutation is not consistently found to be a cause of advanced fibrosis in patients with chronic HCV infection. Firstly, most studies have effectively sought an association of advanced fibrosis with the heterozygous HFE-C282Y state as homozygotes for the HFE-C282Y mutation and compound heterozygotes, carrying one abnormal allele of both the HFE-H63D and HFE-C282Y, are relatively rare among the population with HCV infection. It is generally accepted that people who are heterozygous for the HFEC282Y mutation or homozygous for the HFE-H63D mutation do not develop iron overload. Secondly, iron overload is not an inevitable consequence of being homozygous for the HFE-C282Y mutation. Among patients who carry the disease genotype, HFE-282YY, the proportion who develop either biochemical abnormalities or liver disease is clearly $<100 \%$. In a populationbased study, biochemical expression of disease, as determined by transferrin saturation of $>50 \%$, was found in $50 \%$ of male homozygotes and $40 \%$ of female homozygotes. ${ }^{20}$ Three large populationbased studies found low rates of penetrance for clinical liver disease, as determined by abnormal liver function tests or clinical symptoms, in HFE-282YY homozygotes. ${ }^{20-22}$ In contrast, two smaller, less well controlled, studies found higher rates of clinical disease penetrance. ${ }^{23} 24$ As penetrance of the HFE mutations is low and the heterozygous state is not associated with iron overload then it should not be surprising that HFE does not consistently influence the severity of HCV infection.

Mutations in the haemoglobin genes that cause thalassaemia are strongly associated with heavy iron overload and the penetrance of these mutations is high. The strong erythropoietic drive produced by the haemoglobinopathies suppresses hepcidin expression in the liver leading to high rates or iron absorption from the gastrointestinal tract. ${ }^{25}$ Thalassaemia major has previously been reported as a risk factor for advanced liver disease in patients with HCV infection. ${ }^{26}$ In this issue of Gut, Sartori et al ${ }^{19}$ (see page 693) publish a study in which they have explored the importance of haemoglobin $\beta$ mutations in the development of hepatic iron overload and advanced fibrosis in patients with chronic HCV infection in Italy. As mentioned earlier, HFE mutations were not found to correlate with iron loading or with fibrosis stage but heterozygous carriers of $\beta$-globin mutations were found to have higher hepatic iron concentrations, stainable hepatic iron and more advanced fibrosis than patients with HCV-infection who had wild-type haemoglobin genes and HFE heterozygotes. The prevalence of $\beta$-globin mutations was much higher than what would normally be expected in the Italian population, which may be the result of a bias introduced by using a clinic-based population and the risk of bloodborne virus infection in patients with thalassaemia. ${ }^{27}$ 
The difference in the effect of HFE and $\beta$-globin mutations emphasise the central importance of iron in the development of advanced liver disease associated with HCV infection. It has been reported that iron increases the replication of $\mathrm{HCV}$, possibly through the induction of translation initiation factor $3 .^{28}{ }^{29}$ However, levels of viraemia have not been correlated with histological severity and an alternative explanation must be proposed to explain the advanced liver disease associated with iron excess. HCV itself seems to be a cause of oxidative stress. ${ }^{30}$ Histological examination of $\mathrm{HCV}$-infected liver frequently shows steatosis and mitochondrial swelling: hallmarks of oxidative damage. Transgenic mice expressing either the HCV nucleocapsid or the complete polyprotein also show mitochondrial damage and excess oxidative damage. It therefore seems likely that HCV and iron act synergistically to increase oxidative damage, and to accelerate liver fibrosis and the progression of disease. In support of this hypothesis, mice transgenic for the HCV core protein have high levels of hydroperoxides, lysosomal and mitochondrial membrane damage and deletion of mitochondrial DNA. ${ }^{31}$ These mice go on to develop hepatocellular carcinoma. ${ }^{31}$ Mice transgenic for the complete polyprotein have high levels of lipid peroxidation and develop hepatocellular carcinoma when iron overload is induced. ${ }^{32}$

Although HCV infection cannot always be eliminated iron overload is a treatable condition. Dietary iron restriction and phlebotomy reduce serum iron indices and reduce transaminase levels in patients with HCV infection. ${ }^{33}{ }^{34}$ Furthermore, levels of hepatic lipid peroxidation and histological severity may be improved by phlebotomy in patients without $\beta$ thalassaemia. In patients with thalassaemia, phlebotomy may not be feasible but iron chelation therapy with desferrioximine or the oral chelator deferiprone does seem to prevent the progression of liver fibrosis in patients with HCV infection, and is therefore indicated in patients where the HCV infection cannot be eliminated..$^{35} 36$

Gut 2007;56:613-614.

doi: 10.1136/gut.2006.113076

Correspondence to: Professor M Thursz, Gastroenterology and Hepatology Research,
Imperial College St Mary's Hospital Campus, Norfolk Place, London W2 1NY, UK; m.thursz@ imperial.ac.uk

Competing interests: None.

\section{REFERENCES}

1 Bacon BR, Tavill AS, Brittenham GM, et al. Hepatic lipid peroxidation in vivo in rats with chronic iron overload. J Clin Invest 1983;71:429-39.

2 Galli A, Svegliati-Baroni G, Ceni E, et al. Oxidative stress stimulates proliferation and invasiveness of hepatic stellate cells via a MMP2-mediated mechanism. Hepatology 2005;41:1074-84.

3 Tavill AS, Qadri AM. Alcohol and iron. Semin Liver Dis 2004;24:317-25.

4 Bonkovsky HL, Troy N, McNeal K, et al. Iron and HFE or TfR 1 mutations as comorbid factors for development and progression of chronic hepatitis C. J Hepatol 2002;37:848-54.

5 Fernandez-Rodriguez CM, Gutierrez ML, Serrano $\mathrm{PL}$, et al. Factors influencing the rate of fibrosis progression in chronic hepatitis C. Dig Dis Sci 2004;49: 1971-6.

6 Lin TJ, Liao LY, Lin SY, et al. Influence of iron on the severity of hepatic fibrosis in patients with chronic hepatitis C. World J Gastroenterol 2006; 12:4897-901.

7 Rigamonti C, Andorno S, Maduli E, et al. Iron, hepatic stellate cells and fibrosis in chronic hepatitis C. Eur J Clin Invest 2002;32(Suppl 1):28-35.

8 Thorburn D, Curry G, Spooner R, et al. The role of iron and haemochromatosis gene mutations in the progression of liver disease in chronic hepatitis C. Gut 2002;50:248-52.

9 Wright M, Goldin R, Fabre A, et al. Measuremen and determinants of the natural history of liver fibrosis in hepatitis $C$ virus infection: a cross sectional and longitudinal study. Gut 2003;52:574-9.

10 Poynard T, Bedossa P, Opolon P. Natural history of liver fibrosis progression in patients with chronic hepatitis C. The OBSVIRC, METAVIR, CLINIVIR, and DOSVIRC groups. Lancet 1997;349:825-32.

11 Ryder SD, Irving WL, Jones DA, et al. Progression of hepatic fibrosis in patients with hepatitis C: a prospective repeat liver biopsy study. Gut 2004;53:451-5.

12 Hillebrandt $\mathrm{S}$, Wasmuth HE, Weiskirchen R, et al. Complement factor 5 is a quantitative trait gene that modifies liver fibrogenesis in mice and humans. Nat Genet 2005;37:835-43.

13 Wright M, Goldin R, Hellier S, et al. Factor V Leiden polymorphism and the rate of fibrosis development in chronic hepatitis $C$ virus infection. Gut 2003;52:1206-10.

14 Huang $\mathrm{H}$, Shiffman ML, Cheung RC, et al. Identification of two gene variants associated with risk of advanced fibrosis in patients with chronic hepatitis C. Gastroenterology 2006; 130:1679-87.

15 Smith BC, Gorve J, Guzail MA, et al. Heterozygosity for hereditary hemochromatis is associated with more fibrosis in chronic hepatitis $C$. Hepatology 1998;27:1695-9.

16 Martinelli AL, Franco RF, Villanova MG, et al. Are haemochromatosis mutations related to the severity of liver disease in hepatitis $C$ virus infection? Acta Haematol 2000; 102:152-6.

17 Tung BY, Emond MJ, Bronner MP, et al. Hepatitis C iron status, and disease severity: relationship with HFE mutations. Gastroenterology 2003;124:318-26.
18 Hohler $\mathrm{T}$, Leininger $\mathrm{S}$, Kohler $\mathrm{HH}$, et al. Heterozygosity for the hemochromatosis gene in liver diseases--prevalence and effects on liver histology. Liver 2000;20:482-6.

19 Sartori M, Andorno S, Pagliarulo M, et al Heterozygous $B$ globin gene mutations as a risk factor for iron accumulation and liver fibrosis in chronic hepatitis C. Gut 2007;56:693-8.

20 Beutler E, Felitti VJ, Koziol JA, et al. Penetrance of 845G--> A (C282Y) HFE hereditary haemochromatosis mutation in the USA. Lancet 2002;359:21 1-18.

21 Waalen J, Felitti V, Gelbart T, et al. Prevalence of hemochromatosis-related symptoms among individuals with mutations in the HFE gene. Mayo Clin Proc 2002;77:522-30.

22 Waalen J, Felitti V, Gelbart T, et al. Penetrance of hemochromatosis. Blood Cells Mol Dis 2002;29:418-32.

23 Bulaj ZJ, Ajioka RS, Phillips JD, et al. Disease-related conditions in relatives of patients with hemochromatosis. NEngl J Med 2000;343:1529-35.

24 Olynyk JK, Cullen DJ, Aquilia S, et al. A population-based study of the clinical expression of the hemochromatosis gene. N Engl J Med 1999;341:718-24.

25 Kattamis A, Papassotiriou I, Palaiologou D, et al. The effects of erythropoetic activity and iron burden on hepcidin expression in patients with thalassemia major. Haematologica 2006;91:809-12.

26 Angelucci E, Muretto $P$, Nicolucci A, et al. Effects of iron overload and hepatitis $C$ virus positivity in determining progression of liver fibrosis in thalassemia following bone marrow transplantation. Blood 2002;100:17-21.

27 Vento S, Cainelli F, Cesario F. Infections and thalassaemia. Lancet Infect Dis 2006:6:226-33.

28 Theurl I, Zoller H, Obrist P, et al. Iron regulates hepatitis $C$ virus translation via stimulation of expression of translation initiation factor 3. J Infect Dis 2004; 190:819-25.

29 Kakizaki S, Takagi H, Horiguchi N, et al. Iron enhances hepatitis $C$ virus replication in cultured human hepatocytes. Liver 2000;20:125-8.

30 Choi J, Ou JH. Mechanisms of liver injury. III. Oxidative stress in the pathogenesis of hepatitis $C$ virus. Am J Physiol Gastrointest Liver Physiol 2006;290:G847-51.

31 Moriya K, Nakagawa K, Santa T, et al. Oxidative stress in the absence of inflammation in a mouse mode for hepatitis $C$ virus-associated hepatocarcinogenesis. Cancer Res 2001;61:4365-70.

32 Furutani T, Hino K, Okuda M, et al. Hepatic iron overload induces hepatocellular carcinoma in transgenic mice expressing the hepatitis $C$ virus polyprotein. Gastroenterology 2006; 130:2087-98.

33 Di Bisceglie AM, Bonkovsky HL, Chopra S, et al. Iron reduction as an adjuvant to interferon therapy in patients with chronic hepatitis $C$ who have previously not responded to interferon: a multicenter, prospective, randomized, controlled trial. Hepatology 2000;32:135-8.

34 Iwasa M, Kaito M, Ikoma J, et al. Dietary iron restriction improves aminotransferase levels in chronic hepatitis $C$ patients.

Hepatogastroenterology 2002;49:529-31

35 Wanless IR, Sweeney G, Dhillon AP, et al. Lack of progressive hepatic fibrosis during long-term therapy with deferiprone in subjects with transfusion-dependent beta-thalassemia. Blood 2002;100:1566-9.

36 Wu SF, Peng CT, Wu KH, et al. Liver fibrosis and iron levels during long-term deferiprone treatment of thalassemia major patients. Hemoglobin 2006;30:215-18. 